\title{
A Variant of Poland's syndrome - Case Report and Review of Literature
}

\author{
R K Rauniyar ${ }^{1}$, S Baboo ${ }^{1}$, U Sharma ${ }^{2}$, M Garg
}

${ }^{1}$ B.P.Koirala Institute of Health Sciences, Dharan, ${ }^{2}$ B\&B Hospital Teaching Hospital, Lalitpur

\begin{abstract}
Poland's syndrome is the association of congenital thoracic abnormalities with ipsilateral syndactyly along with various other associated anomalies. A variant of Poland's syndrome without syndactyly along with review of literature is presented here. Various associated anomalies of the syndrome is summarized. Syndactyly believed to be constant features in Poland's Syndrome in earlier reports, may not be present.
\end{abstract}

Keywords: Variant of Poland's Syndrome, Poland's Syndrome without syndactyly, absent pectoralis muscles.

\section{Introduction}

Poland's syndrome constitutes the association of congenital thoracic abnormalities with ipsilateral syndactyly where computed Tomography (CT) clearly demonstrates the extent of soft tissue and skeletal abnormalities of the chest wall. This condition was first described by Alfred Poland in 1841 and the term Poland's syndactyly was first used to describe this group of congenital anomalies by Clarkson in 1962. Baudinne et al (1967) reported a case of "Poland's Syndrome", a term that is more accurate because the group of anomalies include more than just syndactyly. We present a variant of Poland's syndrome without syndactlyly with review of literature.

Correspondence to: Dr. R. K. Rauniyar

Professor and Head

Department of Radiodiagnosis and Imaging

BPKIHS, Dharan Nepal

Email: rauniyar99@yahoo.com

\section{Case Report}

A 26 years old male farmer sustained an injury in the back due to fall from a tree. The clinical examination revealed diffuse

swelling and tenderness in the dorso-lumbar region without any paraplegia. The roentgenograms showed a stable anterior wedge compression fracture of Lumbar one vertebra.

On further clinical examination, it was found that the patient had hypoplastic left hand with hollowness in the ipsilateral infraclavicular area (Fig.1). The anterior fold of left axilla was absent indicating the absence of the sternocostal portion of pectoralis major muscle. The clavicle, acromion and contours of the shoulder were comparable on both sides. There was no evidence of polydactyly or syndactyly and no peripheral neurovascular deficit. There was hypoplasia of the thenar and hypothenar eminence with mild degree of wasting of arm and forearm group of muscles. The patient had no significant difficulty in performing his activities of daily living except for some 
difficulty in lifting heavy weights with left hand. The ring finger was found to be the longest finger in the left hand.

The standard roentgenograms of both hands revealed shortening of the metacarpals, proximal, middle and distal phalanges of left hand as compared to the right hand (Fig.2). The shortening was more marked in the middle phalanges. The standard roentgenograms of chest-PA view did not reveal any bony abnormality. The ultrasound of the abdomen was found to be normal.

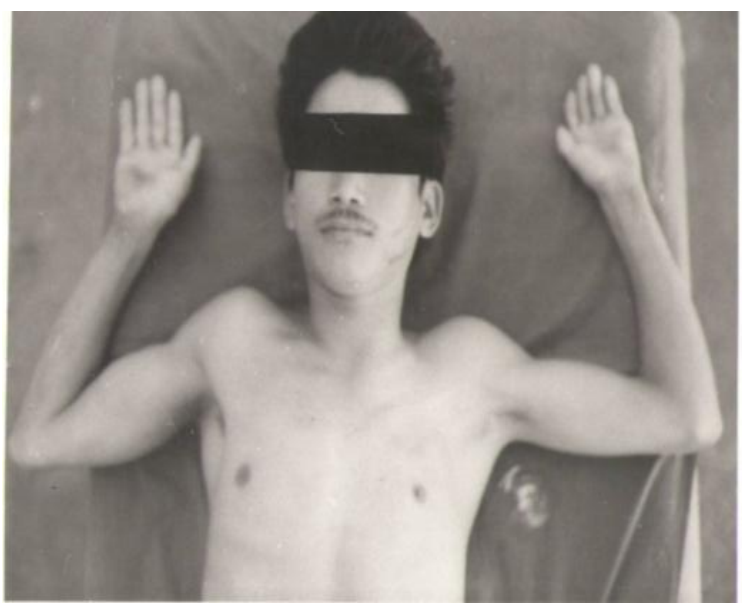

Figure 1: Hypoplastic hand with absent anterior axillary fold with hollowness in the infraclavicular fossa on left side.

The CT scan of chest revealed the absence of sternocostal and clavicular head of pectoralis major and the absence of pectoralis minor on left side (Fig.3). The heart, lungs and posterior mediastinum were found to be normal.

The most significant feature on CT scan measurement was that the tubular bones of left hand were smaller in length and maximum shortening was present in the middle phalanges (table-I).

\section{Discussion}

The etiology of Poland syndrome is unknown. Although hereditary traits have been demonstrated for some anomalies of hands such as polydactyly ${ }^{1}$. The main features of Poland's syndrome are shown in Table- $2^{2-10}$. Other rare associations have been described including cardiac and urological abnormalities, acute leukemia, lymphoma, spherocytosis, mobius syndrome, inguinal hernia, knee flexion contracture, deformity of external ear, club foot and syndactyly of the toes $^{2-3,11-13}$. The right side is more often affected than the left $^{3}$, but in our case involvement was in the left side.

There were no features of syndactyly in our case. There was disproportionate hypoplasia of the middle phalanges of the ipsilateral hand. Thus contrary to earlier belief, syndactyly is not a constant feature of Poland's syndrome ${ }^{4-8}$. The most constant features in Poland's syndrome are hypoplasia or aplasia of the sternocostal portion of the pectoralis major and middle phalanges of the involved hand ${ }^{3-4}$. CT clearly demonstrates the extent of the soft tissue abnormality in this condition ${ }^{4,8}$. In our case CT revealed the absence of both sternocostal and clavicular head of pectoralis major and absence of pectoralis minor which may be difficult to detect clinically.

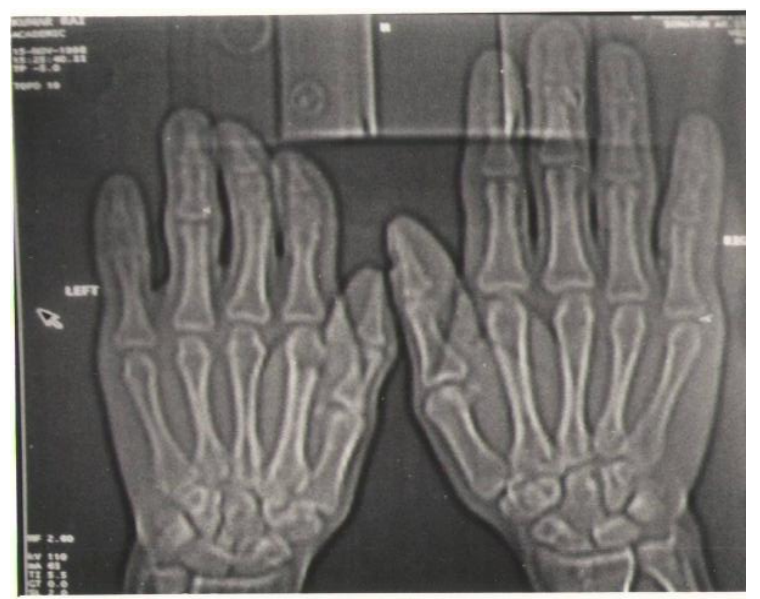

Figure 2: Roentgenogram showing
shortening of metacarpals, proximal,
middle and distal phalanges of left hand.

Although patients with Poland's syndrome rarely have significant functional problems due to the muscle disorders, they may seek a surgical opinion for cosmetic reasons, particularly in the case of females with breast 
Table - I: Measurements (in cms) of lengths of individual bones of both upper limbs.

\begin{tabular}{|c|c|c|c|c|c|c|c|c|}
\hline & & & Right & & Left & & & \\
\hline Humerus & & & 27.6 & & 27.6 & & & \\
\hline Radius & & & 20.7 & & 20.2 & & & \\
\hline Ulna & & & 23.2 & & 22.7 & & & \\
\hline Digits & $\mathrm{MC}$ & PP & MP & DP & $\mathrm{MC}$ & PP & MP & DP \\
\hline $1^{\text {st }}$ & 3.6 & 2.5 & -- & 2.0 & 3.0 & 1.7 & -- & 1.7 \\
\hline $2^{\text {nd }}$ & 5.7 & 3.4 & 2.0 & 1.5 & 5.2 & 2.9 & 0.7 & 1.0 \\
\hline \multicolumn{9}{|l|}{$3^{\text {rd }}$} \\
\hline & 5.0 & 3.8 & 2.4 & 1.6 & 5.0 & 3.3 & 0.9 & 1.2 \\
\hline \multicolumn{9}{|l|}{$4^{\text {th }}$} \\
\hline & 4.8 & 3.6 & 2.2 & 1.5 & 4.5 & 3.3 & 1.6 & 1.5 \\
\hline $5^{\prime}$ & 4.5 & 2.8 & 1.6 & 1.3 & 4.3 & 2.6 & 0.8 & 1.2 \\
\hline
\end{tabular}

MC: Metacarpa1, PP: Proximal phalanx, MP: Middle phalanx, DP: Distal phalanx

Table II: The principle abnormalities in Poland's syndrome. (All anomalies are ipsilateral).

\begin{tabular}{|c|c|}
\hline Muscle abnormalities & $\begin{array}{l}\text { - absent sternocostal head of pectoralis major. } \\
\text { - Rarely absent clavicular head of pectoralis major. } \\
\text { - Absent pectoralis minor } \\
\text { - Hypoplasia of serratus anterior, latissimus dorsi, external } \\
\text { oblique and intercostals, deltoid, infra and supraspinatus }\end{array}$ \\
\hline Mammary abnormalities & $\begin{array}{l}\text { - breast absence or hypoplasia } \\
\text { - Nipple: elevated, hypoplastic }\end{array}$ \\
\hline Thoracic cage defects & $\begin{array}{l}\text { - hypoplasia of hemithorax or ribs, } \\
\text { - Pectus excavatum, pectus carinatum } \\
\text { - Scoliosis } \\
\text { - Scapula: elevated, hypoplastic } \\
\text { - lung herniation } \\
\text { - Partial defect of the diaphragm with thoracic migration of the } \\
\text { liver } \\
\text { - Dextrocardia }\end{array}$ \\
\hline \multirow[t]{2}{*}{ Upper limb defects: Arm } & $\begin{array}{l}\text { - hypoplasia } \\
\text { - contracture of anterior axillary web or band. }\end{array}$ \\
\hline & $\begin{array}{l}\text { - hypoplasia } \\
\text { - Differential radial hypoplasia } \\
\text { - Differential ulnar hypoplasia } \\
\text { - Hypoplasia of the proximal radio-ulnar joint } \\
\text { - Subluxating humero-ulnar joint } \\
\text { - Proximal radio-ulnar synostosis }\end{array}$ \\
\hline Wrist & $\begin{array}{l}\text { - Hypoplasia of carpal bones } \\
\text { - Bony coalitions }\end{array}$ \\
\hline Hand & $\begin{array}{l}\text { - Hypoplasis } \\
\text { - Syndactyly: Simple, Complete or incomplete } \\
\text { - Disproportionate hypoplasis/aplasia of middle phalanges } \\
\text { Thumb; Hypoplastic, supinated, in same plane as the fingers } \\
\text { - Shallow first web space } \\
\text { - Delta shaped phalanx deformity } \\
\text { - Camptodactyly, polydactyly } \\
\text { - Construction rings } \\
\text { - Congenital dislocation of metacarpo-phalangeal joint }\end{array}$ \\
\hline
\end{tabular}


absence. These can be successfully corrected with an ipsilateral pedicled latissimus dorsi flap and submuscular augmentation ${ }^{14}$.

In conclusion, the two most constant features in Poland's syndrome are hypoplasia or aplasia of the sternocostal portion of the pectoralis major and hypoplasia or aplasia of the middle phalanges of the ipsilateral hand. Syndactyly, believed to be constant feature in earlier reports may not be present. CT can accurately demonstrate the extent of the muscle abnormalities in Poland's syndrome and provide useful information for planning reconstructive surgery.

\section{References}

1. Wassel HD. Results of surgery for polydactyly of the thumb. A review. Clinical orthop.1969; 64:175-193.

2. Mace JW, Kaplan JM, Schanberger JE and Gotlin RW. Poland's syndrome: report of seven cases and review of the literature. Clinical pediatrics. 1972; 11:98.

3. Ireland DCR, Noria Takayama, Flatt AE. Poland's syndrome. A review of 43 cases. J. Bone and Joint Surg. 1976; 58:52-58.

4. Suzuki T, Takazawa H, Koshino T. Computed Tomography of the pectoralis muscle in Poland's syndrome. Hand. 1983;15:35-41

5. Gausewitz SH, Meals RA, Setoguchi Y. Severe limb deficiency in Poland's syndrome. Clinical Orthopaedics. 1984; 185:9-13.

6. Gugliantini P, Sagni L, Parri C, Seganti G, Cavalletti P. A new multiple

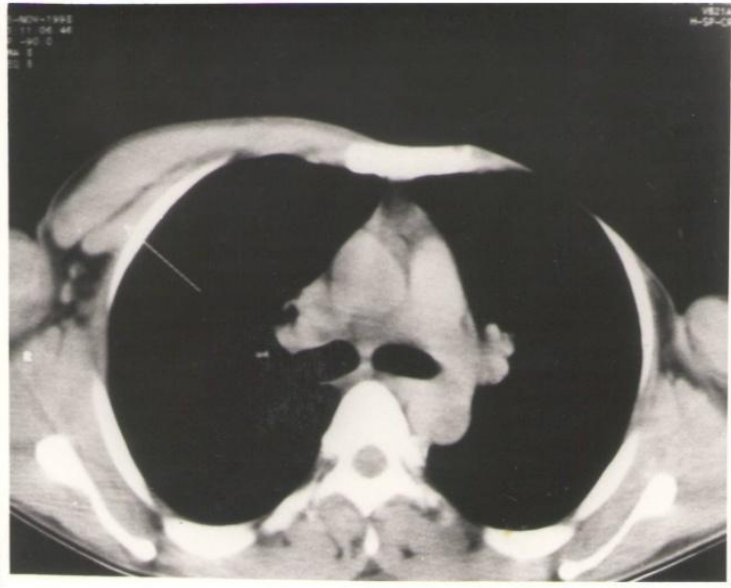

Figure3: CT scan showing normal pectoralis major and pectoralis minor (arrow) on right side and absent pectoral muscles on left side.

abnormality complex similar to Poland's syndrome. Pediatr-Med-Chir. 1984; 6:299- 302.

7. Wilson MR, Louis DS, Stevenson TR. Poland's syndrome; variable expression and associated anomalies. J-Hand-SurgAm. 1998; 13:880-82.

8. Bainbridge LC, Wright AR, Kanthan R. Computed tomography in the preoperative assessment of Poland's syndrome. Br-J-Plast-Surg. 1991; 44:604-607.

9. Poullin $\mathrm{P}$, Toussirot E, Schiano A, Serratrice 0. Complete and dissociated forms of Poland's syndrome. RevRhum-Mal-Osteoartic. 1992; 59: 114120.

10. Fabian MC, Fisher JD. A variant of Poland's syndrome. Can-J-Surg. 1994; 37:67-69.

11. Walters JR, Reddy BN, Bailon A, Vitale LF. Poland's syndrome associated with leukemia (Letter). Journal of Pediatrics. 1973; 82: 889. 
12. Hanka SS. Dextrocardia associated with Poland's syndrome. Journal of Pediatrics. 1975; 86:312.

13. Miller RA and Miller DR. Congenital absence of the pectoralis major muscle with acute lymphoblastic leukemia and genitourinary abnormalities. Journal of Pediatrics. 1975; 87:146.
14. Hester TR. Jr., and Bostwick J. Poland's syndrome: Correction with latissimus muscle transposition. Plastic and Reconstructive Surgery. 1982;69:226 